\title{
A Comprehensive Review of Trichosporon spp.: An Invasive and Emerging Fungus
}

\author{
Vibha Mehta ${ }^{1}$, Charu Nayyar ${ }^{2}$, Neelam Gulati ${ }^{3}$, Nidhi Singla ${ }^{4}$, Sunvir Rai ${ }^{5}$, Jagdish Chandar ${ }^{3}$ \\ 1. Infectious Diseases, Institute of Liver and Biliary Sciences, New Delhi, IND 2. Clinical Microbiology, Medanta SN \\ Superspeciality Hospital, Sriganganagar, IND 3. Clinical Microbiology, Government Medical College \& Hospital, \\ Chandigarh, Chandigarh, IND 4. Microbiology, Government Medical College \& Hospital, Chandigarh, Chandigarh, IND \\ 5. Preventive and Social Medicine, Government Medical College, Patiala, Patiala, IND
}

Corresponding author: Neelam Gulati, drneel222@gmail.com

\begin{abstract}
Trichosporon species are basidiomycetous yeast-like organisms found ubiquitous in nature. They are increasingly been recognized as opportunistic pathogens capable of causing life-threatening invasive diseases (trichosporonosis), especially in immuno-suppressed patients and rarely in immuno-competent patients too. Earlier multiple members of the genus Trichosporon were clubbed together as T. beigelli but after the advent of molecular techniques, more than 50 different subspecies and around 16 different strains causing human diseases are reported. It is known to cause a wide range of diseases, from superficial to probable and proven invasive diseases to summer hypersensitivity. The ability of Trichosporon strains to form biofilms on implanted devices, glucuronoxylomannan in their cell walls, and production of proteases and lipases lead to the virulence of this genus. This ubiquitous fungus exhibits intrinsic resistance to echinocandins, variable minimum inhibitory concentrations (MIC) for amphotericin B, and moderate susceptibility to fluconazole and Itraconazole, which are the commonly used anti-fungal agents for any invasive fungal infections which lead to the re-emergence of this notorious yet neglected pathogen and hence the reports of breakthrough infections among patients receiving these antifungals. This review is to understand the epidemiological, clinical details, and antifungal susceptibility pattern of various Trichosporon infections and it highlights the importance of early detection and treatment for this emerging yeast and also will add to the ongoing surveillance for the anti-fungal susceptibility pattern for this fungus.
\end{abstract}

Review began 07/19/2021 Review ended 08/19/2021 Published 08/21/2021

\section{(๑) Copyright 2021}

Mehta et al. This is an open access article distributed under the terms of the Creative Commons Attribution License CC-BY 4.0., which permits unrestricted use, distribution, and reproduction in any medium, provided the original author and source are credited.
Categories: Infectious Disease, Transplantation, Public Health

Keywords: trichosporon, antifungal susceptibility, invasive trichosporonosis, minimum inhibitory concentration, emerging yeast, trichosporon asahii

\section{Introduction And Background}

The word Trichosporon, a combination of two Greek words Trichos (hair) and sporon (spores) was first discovered by Biegel in 1865, who observed that this organism caused benign hair infection. The superficial fungal infection caused by the genus Trichosporon started to be known as white piedra (meaning "stone") because of the presence of hard and irregular nodules along the hair [1]. But over the last few decades, Trichosporon spp. has increasingly been recognized as opportunistic pathogens capable of causing life-threatening invasive diseases, not just in immunosuppressed but also in immunocompetent patients [1].

In 1902, all Trichosporon species were designated as Trichosporon beigelii, yeast containing arthrospores, by Vuillemin [1]. Another species was discovered from a patient with pruritic cutaneous lesions in 1909 by Buermann et al., which was designated by Ota in 1926 as Trichosporon cutaneum [2]. Further in 1942, two scientists Diddens and Lodder found these two species to be the same. Thus the use of two terminologies for the same organism i.e T. beigelli preferred by the physicians and T. cutaneum by the mycologists [2].

The above nomenclature was considered inappropriate and thus abandoned when in 1992 after Gueho et al. explained that the two species to be completely non-related as detected by the ubiquinone system and percentage of GC content. Eventually, in 1994, it was defined that the genus Trichosporon mainly included six major pathogenic species: T. asahii, T. asteroides, T. cutaneum, T. mucoides, T. inkin and T. ovoides [3]. Even more recently T. loubieri, and T. pullulans have been reported as major causes of invasive infection. It was concluded that the genus Trichosporon has 50 species, four clades, which includes 16 species of clinical relevance [1].

\section{Review}

\section{Pathogenicity}

Trichosporon is a part of the normal flora of the human skin, vagina, and gastrointestinal tract [4]. The infections caused by Trichosporon spp. can be broadly categorized as: 
The most common clinical presentation of superficial Trichosporon infection is benign irregular nodules on the hair shaft lesions called white piedra [4]. Despite the "stony" name, nodules have a soft texture and are loosely attached to the shaft, and vary from white to light brown in color. This disease has a primary predisposition towards children and young adults from tropical and temperate areas and mostly affects females using headbands frequently [5]. White piedra is mainly caused by T. cutaneum, T. inkin, T. ovoides, and T. loubieri [3]. It may affect the scalp, beard, mustache, eyebrows, axilla, and even genital hairs [6]. Another common presentation of superficial infection caused by Trichosporon is onychomycosis, and the common causative agent is T. cutaneum [7].

\section{b) Invasive Infections}

In patients with underlying history of hematological cancer, Trichosporon spp. is second common to Candida in causing disseminated yeast infections. The mortality attributed to Trichosporon spp. in such patients, in spite of the antifungal therapy is very high and ranges from 50-80\% [8]. Breakthrough trichosporonosis has been colossally reported commonly in immunocompromised patients especially after the administration of ineffective antifungal treatment by amphotericin B, echinocandins, and rarely triazoles [1]. Disseminated trichosporonosis may affect a wide array of organs and the presentation may vary from brain abscess, meningitis, endophthalmitis, pneumonia, soft tissue lesions, lymphadenopathy, endocarditis, arthritis, esophagitis, liver, and splenic abscess, or even uterine infections [1].

As per the European Organization for Research and Treatment of Cancer/Invasive Fungal Infection Cooperative Group (EORTC/IFICG) and the National Institute of Allergy and Infectious Disease Mycoses Study Group (NIAID/MSG), invasive trichosporonosis has been classified as follows [1,9]:

1. Proven invasive trichosporonosis - patients presenting with at least one of the following criteria:

i) Blood cultures yielding Trichosporon species in patients with temporally related clinical signs and symptoms of infection

(ii) Cerebrospinal fluid (CSF) cultures yielding Trichosporon species,

(iii) Biopsy specimens that are culture positive and present histopathological evidence of fungal elements compatible with Trichosporon species.

2. Probable invasive trichosporonosis - patients presenting all of the following criteria:

(i) Presence of at least one host factor (therapy with immunosuppressive drugs, neutropenia, or persisting fever despite therapy with appropriate broad-spectrum antibiotics

(ii) One microbiological criterion (culture or presence of fungal elements compatible with Trichosporon in a suspect sample)

(iii) One major clinical criterion (imaging or cytobiochemical findings) is consistent with infection.

T. asahii is the most common causative agent of invasive trichosporonosis [1]. Invasion occurs either through the exogenous route when the organism enters through the central lines and catheters through colonized skin or endogenously by translocation through the gut in immunocompromised patients [10]. In very low birth weight (VLBW) babies, the organism may enter either through the mother's genital region or through the hands of health care workers [11].

c) Summer type hypersensitivity

Trichosporon is also attributed as the major etiological agent of summer-type hypersensitivity (SHP) in Japan and T. cutaneum has been named as the main causative agent [12].

\section{Virulence factors}

a) Biofilm

Trichosporon adheres to the implanted devices and forms biofilms. This biofilm helps in the invasion of the surface by evading the host immune response as well as the effect of antifungal drugs. The kinetics of biofilm formation in Trichosporon was first studied by Di Bonaventura et al. on strains that were obtained from blood cultures of patients with hematological malignancies. With the help of electron microscopy, they demonstrated that the biofilm formation of T. asahii strains was similar to that produced by Candida spp. after a 30min incubation. After $72 \mathrm{hrs}$ incubation, T. asahii showed morphologies such as budding yeast cells and filamentous forms, engulfed in an extracellular polysaccharide matrix which was the main constituent of the ultrastructure of a mature biofilm [13]. Various imaging sections taken across the thickness of biofilm 
revealed that the thickness to be somewhere between 25 to $40 \mu \mathrm{m}$. They simultaneously compared the antimicrobial susceptibility pattern of planktonic cells to biofilm cells of Trichosporon spp. for various antifungals like amphotericin B, caspofungin, fluconazole, and voriconazole and found that biofilm cells of T.asahii were highly resistant to all antifungals tested (MIC 1,024 g/ml) and were up to 16,000 times more resistant than planktonic cells to voriconazole (MIC $=0.06 \mathrm{~g} / \mathrm{ml}$ ) [13].

\section{b) Enzymes}

Proteases and phospholipases act by disrupting the proteins of the host cell membrane and thus help in the invasion of the fungus. Their role in pathogenicity varies according to their level of expression and host immune response [14]. Chen et al. in 1994 isolated and purified two lipase enzymes (lipase I and II) from T. fermentans and exhibited that these enzymes were stable even after incubation at $30^{\circ} \mathrm{C}$ for 24 h over a pH range of 4.0 to 8.0 [15].

\section{c) Cell Wall Components}

Similar to C. neoformans, members of the genus Trichosporon also produce glucuronoxylomannan (GXM) in their cell walls. GXM is a 1,3-linked mannan backbone attached to short side chains of 1,4-linked mannose and 1,2-linked xylose residues by substitution of two or four portion of the 1,3-linked mannose residues of the main molecule [16]. It has been demonstrated that GXM enervated the phagocytic nature of neutrophils and monocytes against the fungus [17]. Its presence is associated with infection in C. neoformans, however, this correlation has not been yet established for Trichosporon [1].

\section{d) Adapting Technique}

Members of the genus Trichosporon are ubiquitous in nature and so have a wide range of habitats and environments. This led to an assumption that they are yet less specialized as human pathogens and therefore it has been suggested by various authors that this genus is still in the process of adaptation to the animal host. This hypothesis explains the prominent differences in genome size of Trichosporon and Malassezia. However, extensive research is needed to establish the Trichosporon-host interactions [18].

\section{Laboratory diagnosis}

a) Phenotypic Identification

Yeast-like colonies are isolated on sabouraud dextrose agar. The colonies are cream-colored, however, may darken to yellowish-grey. They are highly wrinkled; the center of the colony becomes heaped and appears folded. The colonies may adhere to and crack the agar [4]. On cornmeal-tween 80 agar, true or pseudohyphae with blastoconidia and arthroconidia singly or in short chains are demonstrated. All species of Trichosporon hydrolyze urea thus differentiating it from Geotrichum, which also produce arthroconidia [4].

The commercial systems most commonly used rapid yeast identification in clinical laboratories are both non-automated like API 20C AUX (bioMe'rieux, France), ID 32C (bioMe'rieux, France), and RapID Yeast Plus system (Innovative Diagnostic System, Norcross, GA) and automated like Vitek Systems (bioMe'rieux, Vitek, Hazelwood, MO) and Baxter Microscan (Baxter Microscan, West Sacramento) [1,19].

\section{b) Molecular Methods}

Though expensive for routine use in developing nations, DNA-based PCR methods are more precise and lead to the accurate identification of Trichosporon species. The targets for species identification and phylogenetic studies are ribosomal genes including alternating conserved regions (D1/D2 region of the 28S rDNA) and variable regions (ITS and IGS1 regions) [20,21]. Conserved D1/D2 region of the $28 \mathrm{~S}$ rDNA) were amplified using six primer sets to make them more sensitive, specific and to shorten the identification span to five hours. Thus the wisest approach is to use these tools as a first screening tool for Trichosporon species in biological samples [22]. Other molecular markers such as mitochondrial cytochrome b (Cyt b) have also been used for the detection of Trichosporon species. Another region of $396 \mathrm{bp}$ fragment of Cyt $\mathrm{b}$ gene was amplified by Biswas et al. in 23 fungal strains and observed that there were 141 variable nucleotide sites (35.6\%) among various Trichosporon strains [23].

\section{c) Antigen Detection}

Beta D glucan and galactomannan are being increasingly used as biomarkers for the early diagnosis of certain invasive fungal infections such as candidiasis and aspergillosis [24]. However, its role in the diagnosis of invasive trichosporonosis is still uncertain. Research from Japan analyzed 33 cases of Trichosporon Fungemia and demonstrated that only $50 \%$ of patients had a single positive test at the time of admission and a few had a positive test before positive blood cultures were obtained [25]. It was demonstrated by Lyman et al. that all Trichosporon strains produced a detectable amount of GXM in their cell wall and so this GXM cross-reacts with $C$. neoformans antigen in sera of patients with invasive trichosporonosis. If structural and 
serological properties of Trichosporon GXM can be studied properly and differentiated from C. neoformans, it can act as a useful tool in early and accurate diagnosis of invasive Trichosporon infection [26].

\section{d) Proteonomics}

Proteonomics works on the principle of protein content detection of a sample using mass spectrometry (MS) [1]. Many software are available for this study, amongst which MALDI BioTyper 2.0 is the most commonly used. This software possesses approximately 3700 profiles in its database. Among these, 274 (7.40\%) represent fungus, of these 11 (4.01\%) are related to Trichosporon species. Out of which six are T. asahii, T. mucoides, T. debeurmannianum, T. inkin, T. ovoides, and T. cutaneum and two are Trichosporon species. The biggest advantage of this method is that it is the least time-consuming. An isolate can be processed and identified within $2 \mathrm{~min}$, making this method a next-generation tool in organism identification [27]. MALDITOF MS promises to be a great tool in organism identification by producing protein fingerprints [1].

The accuracy of detection of Trichosporon species by MALDI-TOF MS was tested by Bader et al. using two commercially available software, MALDI BioTyper2 (Bruker Daltonics) and Saramis (AnagnosTec), for 1,192 clinical yeast isolates which were previously identified by morphological characterization and biochemical tests (API 20 C AUX and ID 32 C galleries) [28]. The consilience among these three different identification methods was $95.1 \%$, and all isolates of $T$. asahii were identified correctly by these three techniques [28].

e) Genotyping of Trichosporon Species

Using the IGS1 sequencing, nine different genotypes of T.asahii, the most important clinical species, have been described [29]. Amongst all the genotypes, genotype 1 is the most predominant type all over the world, ranging from 45 to $80 \%$, except for the US where it has never been isolated. Genotypes 3 and 5 are abundant in the United States [1].

\section{Antifungal susceptibility testing \& antifungal therapy}

Antifungal susceptibility testing of the genus Trichosporon for evaluating the effect of various antifungal drugs is being done as per the Clinical and Laboratory Standards Institute (CLSI) broth microdilution method (2008), which is currently been standardized for Candida species and C. neoformans. European Committee for Antimicrobial Susceptibility Testing (EUCAST) broth microdilution method, a recommendation originally proposed for the genus Candida is also being used though no clear-cut breakpoints have been identified by them $[30,31]$.

Some authors have questioned the accuracy of the broth microdilution method for detecting isolates with resistance to amphotericin B quoting the narrow MIC variation seen in them. Hence clear-cut MIC breakpoints have not been confirmed for amphotericin B [32]. Hence, sensitivities of various species of the genus Trichosporon to commonly used antifungal drugs are still not known. Various studies have found that T. asahii strains are more sensitive to higher azoles and comparatively resistant to amphotericin B than other yeast-like species [1].

All tested T. asahii strains have demonstrated a very high MIC of $\geqslant 2 \mu \mathrm{g} / \mathrm{ml}$ for amphotericin B. Many recent studies have shown a limited role of amphotericin B in vitro and in vivo. Almost all isolates showed resistance to Echinocandins in various studies. However, strains of Trichosporon have shown good susceptibility for voriconazole and posaconazole $[1,33]$. Topical azoles have shown promising results in superficial infections, along with proper personal hygiene which prevents recurrence [31]. For systemic infections, triazoles have better efficacy than amphotericin B. Voriconazole is considered the drug of choice in neutropenic patients with disseminated trichosporonosis [12] [33]. Antifungal treatment in such patients should be continued till the resolution of neutropenia, fever, radiological findings, and negative culture report. Echinocandin is not recommended in the treatment of Trichosporon as its role is very limited.

5flucytosine (5 FC) also does not have any activity against Trichosporon. However, some reports suggest that combination therapy of 5FC and amphotericin B show good results in the treatment of trichosporonosis [34]. Authors also suggest that a combination of echinocandin along with amphotericin B or azoles have shown synergistic antifungal effects [35], but still clear-cut guidelines are awaited, and review studies like these help in deciding the cut off values. The biochemical profile and growth characteristics for Trichosporon identification (Table 1) [36]. 


\section{Cureus}

\begin{tabular}{|c|c|c|c|c|c|c|}
\hline Strains & T. asahii & T. inkin & T. mucoides & T. ovoides & T. asteroides & T. cutaneum \\
\hline \multicolumn{7}{|l|}{ Tests } \\
\hline \multicolumn{7}{|l|}{ Sugar assimilation } \\
\hline Myo- inositol & $\mathrm{V}$ & + & + & + & + & + \\
\hline L- arabinose & + & - & + & - & + & + \\
\hline Sorbitol & $\mathrm{V}$ & $\mathrm{V}$ & + & V & $\mathrm{V}$ & $\mathrm{V}$ \\
\hline Melibiose & - & - & + & - & + & - \\
\hline Growth at $37^{\circ} \mathrm{C}$ & + & + & + & $\mathrm{V}$ & V & - \\
\hline Growth in the presence of $0.1 \%$ cyclohexamide & $\mathrm{N}$ & $\mathrm{V}$ & $\mathrm{N}$ & $\mathrm{N}$ & $\mathrm{N}$ & $\mathrm{N}$ \\
\hline
\end{tabular}

TABLE 1: Biochemical profile and growth characteristics of various Trichosporon spp.[36]

and MICs of Trichosporon spp. for different antifungals studied by various authors have been tabulated in Table 2 for reference [37-47].

\begin{tabular}{|c|c|c|c|c|c|c|c|c|c|c|c|c|}
\hline References & & $\begin{array}{l}\text { Kalkanci et } \\
\text { al. [37] }\end{array}$ & $\begin{array}{l}\text { Leme's } \\
\text { et al. } \\
\text { [38] }\end{array}$ & $\begin{array}{l}\text { Sun } \\
\text { Wei et } \\
\text { al. [39] }\end{array}$ & $\begin{array}{l}\text { Yang et } \\
\text { al. [40] }\end{array}$ & $\begin{array}{l}\text { Arabatzis et } \\
\text { al. [41] }\end{array}$ & $\begin{array}{l}\text { Taverna } \\
\text { et al. [42] }\end{array}$ & $\begin{array}{l}\text { Montoya } \\
\text { et al. } \\
\text { [43] }\end{array}$ & $\begin{array}{l}\text { Almeida } \\
\text { et al. } \\
{[44]}\end{array}$ & $\begin{array}{l}\text { Rastogi } \\
\text { et al. } \\
\text { [45] }\end{array}$ & $\begin{array}{l}\text { Singh } \\
\text { S et al. } \\
{[46]}\end{array}$ & $\begin{array}{l}\text { Mehta V } \\
\text { et al. } \\
{[47]}\end{array}$ \\
\hline Year & & 2010 & 2010 & 2012 & 2013 & 2014 & 2014 & 2015 & 2016 & 2016 & 2019 & 2021 \\
\hline Country & & Turkey & Brasil & Beijing & Taiwan & Greece & Argentina & Mexico & Brasil & India & India & India \\
\hline No of isolates & & 107 & 34 & 12 & 32 & 42 & 41 & 39 & 9 & 31 & 24 & 46 \\
\hline \multicolumn{2}{|l|}{ Method Used } & $\begin{array}{l}\text { ASTY } \\
\text { Colorimetric } \\
\text { method }\end{array}$ & CLSI & CLSI & CLSI & $\begin{array}{l}\text { CLSI } \\
\text { EUCAST }\end{array}$ & EUCAST & CLSI & CLSI & CLSI & CLSI & CLSI \\
\hline $\begin{array}{l}\text { Incubation } \\
\text { period }\end{array}$ & & - & $\begin{array}{l}24 \\
\text { hours } \\
\text { and } 48 \\
\text { hours }\end{array}$ & $\begin{array}{l}24-48 \\
\text { hours }\end{array}$ & 48hours & $\begin{array}{l}\text { CLSI=48 } \\
\text { hours } \\
\text { EUCAST=24 } \\
\text { hours }\end{array}$ & $\begin{array}{l}24-48 \\
\text { hours }\end{array}$ & 24 hours & - & - & $\begin{array}{l}24 \\
\text { hours }\end{array}$ & - \\
\hline \multicolumn{13}{|l|}{ Drugs } \\
\hline \multirow{5}{*}{$\begin{array}{l}\text { Amphotericin- } \\
\text { B ( } \mu \mathrm{g} / \mathrm{ml})\end{array}$} & $\begin{array}{l}\text { MIC } \\
\text { Range }\end{array}$ & $0.125-4$ & $\begin{array}{l}24 \\
\text { hours: } \\
0.06-64 \\
48 \\
\text { hours: } \\
0.06-64\end{array}$ & $0.25-1$ & $0.5-4$ & $\begin{array}{l}\text { CLSI: 0.032- } \\
64 \text { EUCAST: } \\
0.064-32\end{array}$ & $0.25-4$ & $0.5-16$ & $0.06-1$ & $\begin{array}{l}0.25->- \\
64\end{array}$ & $\begin{array}{l}0.125- \\
16\end{array}$ & $\begin{array}{l}0.25- \\
\geq 16\end{array}$ \\
\hline & $\begin{array}{l}\text { MIC } \\
50\end{array}$ & 1 & $\begin{array}{l}24 \\
\text { hours: } \\
248 \\
\text { hours: } \\
4\end{array}$ & - & 0.5 & $\begin{array}{l}\text { CLSI: } 2 \\
\text { EUCAST: } 2\end{array}$ & - & 2 & - & 16 & - & 16 \\
\hline & $\begin{array}{l}\text { MIC } \\
90\end{array}$ & 2 & $\begin{array}{l}24 \\
\text { hours: } \\
448 \\
\text { hours: } \\
64\end{array}$ & - & 2 & $\begin{array}{l}\text { CLSI: } 32 \\
\text { EUCAST: } 16\end{array}$ & - & 4 & - & $>16$ & - & 16 \\
\hline & & & $\begin{array}{l}24 \\
\text { hours: }\end{array}$ & & & & & & & & & \\
\hline & $\begin{array}{l}\text { MIC } \\
\text { Range }\end{array}$ & $0.125-32$ & $\begin{array}{l}0.25-32 \\
48\end{array}$ & 1-Aug & - & - & - & Apr-64 & - & - & - & $\begin{array}{l}0.125- \\
\geq 64\end{array}$ \\
\hline
\end{tabular}




\section{Cureus}

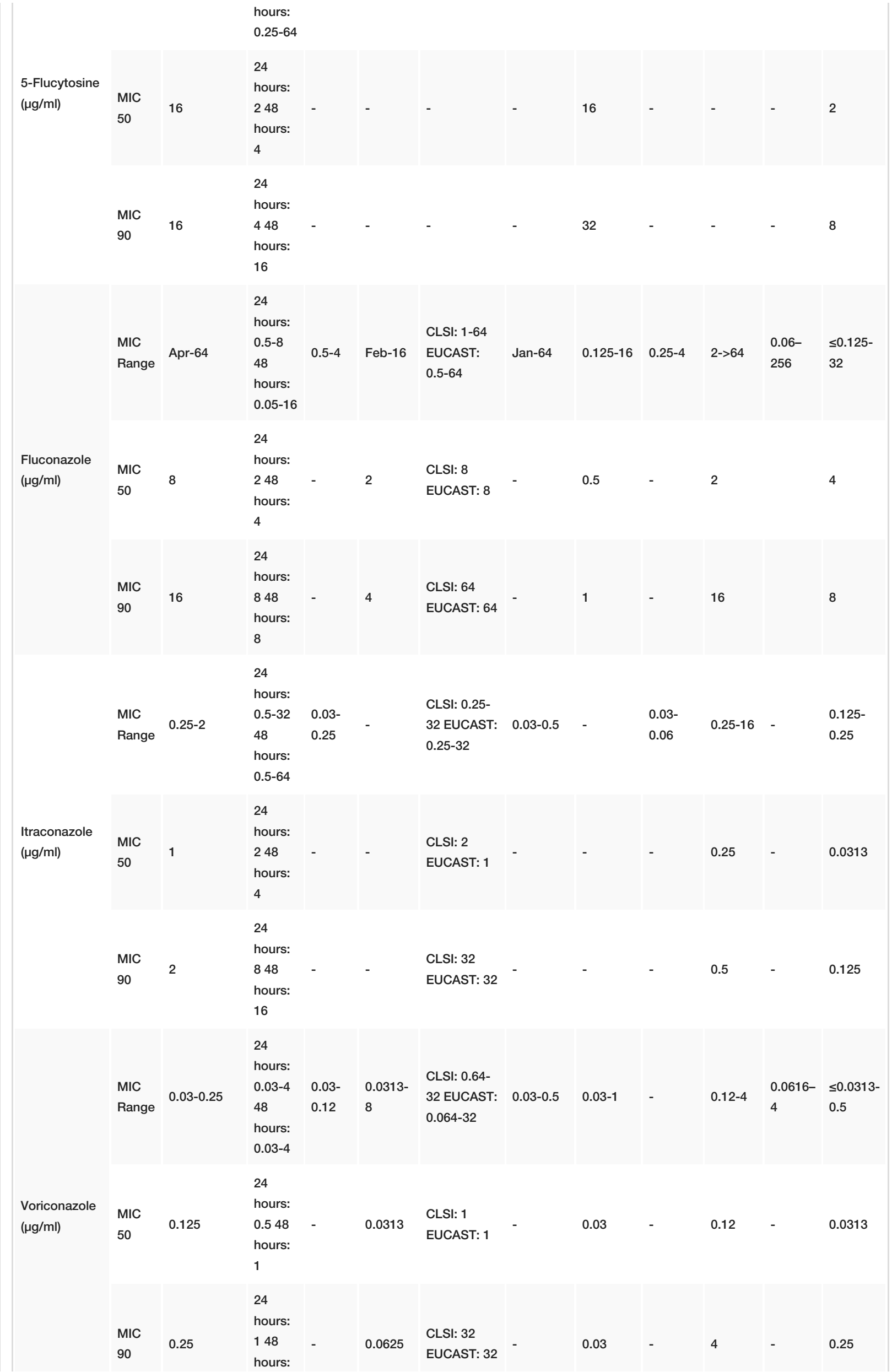




\section{Cureus}

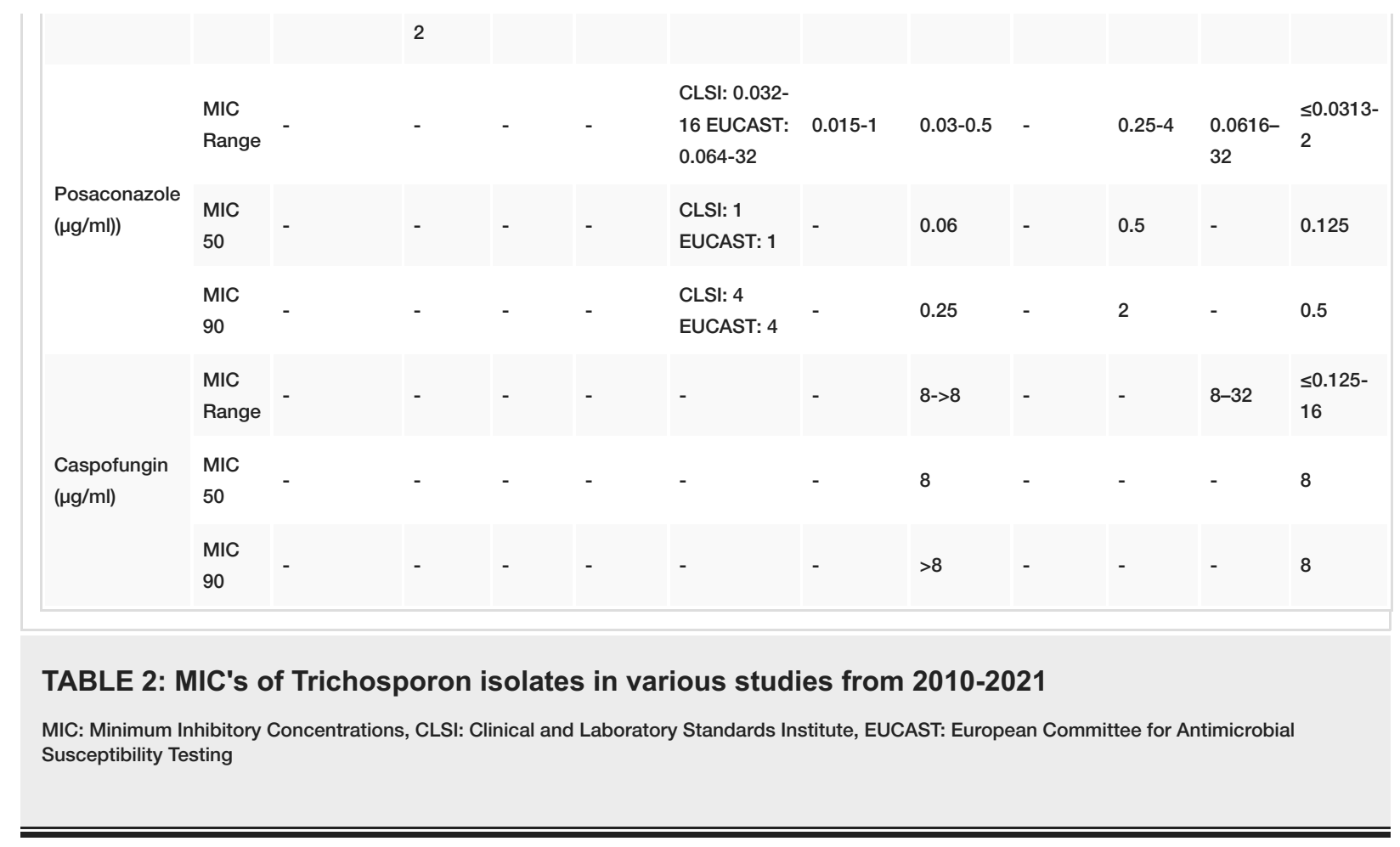

\section{Conclusions}

Trichosporon is an emerging infection presenting more in invasive forms in recent times which is a matter of concern. Its inherent resistance to commonly used antifungals makes it a more grave infection. Prompt diagnosis and timely management will play a key role in dealing with this fungus.

\section{Additional Information}

Disclosures

Conflicts of interest: In compliance with the ICMJE uniform disclosure form, all authors declare the following: Payment/services info: All authors have declared that no financial support was received from any organization for the submitted work. Financial relationships: All authors have declared that they have no financial relationships at present or within the previous three years with any organizations that might have an interest in the submitted work. Other relationships: All authors have declared that there are no other relationships or activities that could appear to have influenced the submitted work.

\section{Acknowledgements}

We would like to acknowledge Dr. Ankita Tukanayat for her expert guidance and our technical staff Mrs. Ruby and Mr. Sheetal for their constant support.

\section{References}

1. Colombo AL, Padovan AC, Chaves GM: Current knowledge of trichosporon spp. and trichosporonosis . Clin Microbiol Rev. 2011, 24:682-700. 10.1128/CMR.00003-11

2. Guého E, de Hoog GS, Smith MT: Neotypification of the genus Trichosporon. Antonie Van Leeuwenhoek. 1992, 61:285-8. 10.1007/BF00713937

3. Guého E, Improvisi L, de Hoog GS, Dupont B: Trichosporon on humans: a practical account . Mycoses. 1994, 37:3-10. 10.1111/j.1439-0507.1994.tb00277.x

4. Chander J: Textbook of medical mycology.. Chander J (ed): Jaypee Publishers, New Delhi; 2018. https://books.google.com.au/books/about/Textbook_of_Medical_Mycology.html? id=OLpEDwAAQBAJ\&redir_esc $=$ y.

5. Gold I, Sommer B, Urson S, Schewach-Millet M: White piedra. A frequently misdiagnosed infection of hair . Int J Dermatol. 1984, 23:621-3. 10.1111/j.1365-4362.1984.tb05704.x

6. Groll AH, Walsh TJ: Uncommon opportunistic fungi: new nosocomial threats. Clin Microbiol Infect. 2001, 7 Suppl 2:8-24. 10.1111/j.1469-0691.2001.tb00005.x

7. Archer-Dubon C, Orozco-Topete R, Leyva-Santiago J, Arenas R, Carbajosa J, Ysunza A: Superficial mycotic infections of the foot in a native pediatric population: a pathogenic role for Trichosporon cutaneum?. Pediatr Dermatol. 2003, 20:299-302. 10.1046/j.1525-1470.2003.20403.x

8. Ruan SY, Chien JY, Hsueh PR: Invasive trichosporonosis caused by Trichosporon asahii and other unusual Trichosporon species at a medical center in Taiwan. Clin Infect Dis. 2009, 49:e11-7. 10.1086/599614

9. De Pauw B, Walsh TJ, Donnelly JP, et al.: Revised definitions of invasive fungal disease from the European Organization for Research and Treatment of Cancer/Invasive Fungal Infections Cooperative Group and the 
National Institute of Allergy and Infectious Diseases Mycoses Study Group (EORTC/MSG) Consensus Group. Clin Infect Dis. 2008, 46:1813-21. 10.1086/588660

10. Chagas-Neto TC, Chaves GM, Colombo AL: Update on the genus Trichosporon. Mycopathologia. 2008, 166:121-32. 10.1007/s11046-008-9136-X

11. Salazar GE, Campbell JR: Trichosporonosis, an unusual fungal infection in neonates . Pediatr Infect Dis J. 2002, 21:161-5. 10.1097/00006454-200202000-00016

12. Ando M, Arima K, Yoneda R, Tamura M: Japanese summer-type hypersensitivity pneumonitis. Geographic distribution, home environment, and clinical characteristics of 621 cases. Am Rev Respir Dis. 1991, 144:7659. 10.1164/ajrccm/144.4.765

13. Ramage G, Rajendran R, Sherry L, Williams C: Fungal biofilm resistance. Int J Microbiol. 2012, 2012:528521. $10.1155 / 2012 / 528521$

14. Ghannoum MA: Potential role of phospholipases in virulence and fungal pathogenesis . Clin Microbiol Rev. 2000, 13:122-43. 10.1128/CMR.13.1.122

15. Chen J, Shimura S, Kirimura K, Usami S: Purification of extracellular lipases from Trichosporon fermentans WU-C12. J Ferment Bioengin. 1994, 77:548-50. 10.1016/0922-338X(94)90126-0

16. Mizobe T, Ando M, Yamasaki H, Onoue K, Misaki A: Purification and characterization of the serotypespecific polysaccharide antigen of Trichosporon cutaneum serotype II: a disease-related antigen of Japanese summer-type hypersensitivity pneumonitis. Clin Exp Allergy. 1995, 25:265-72. 10.1111/j.13652222.1995.tb01039.x

17. Rodrigues ML, Fonseca FL, Frases S, Casadevall A, Nimrichter L: The still obscure attributes of cryptococcal glucuronoxylomannan. Med Mycol. 2009, 47:783-8. 10.3109/13693780902788621

18. Giddey K, Favre B, Quadroni M, Monod M: Closely related dermatophyte species produce different patterns of secreted proteins. FEMS Microbiol Lett. 2007, 267:95-101. 10.1111/j.1574-6968.2006.00541.x

19. Sugita T, Nishikawa A, Shinoda T, Kume H: Taxonomic position of deep-seated, mucosa-associated, and superficial isolates of Trichosporon cutaneum from trichosporonosis patients. J Clin Microbiol. 1995, 33:1368-70. 10.1128/jcm.33.5.1368-1370.1995

20. Sugita T, Nishikawa A, Shinoda T: Rapid detection of species of the opportunistic yeast Trichosporon by PCR. J Clin Microbiol. 1998, 36:1458-60. 10.1128/JCM.36.5.1458-1460.1998

21. Sugita T, Makimura K, Nishikawa A, Uchida K, Yamaguchi H, Shinoda T: Partial sequences of large subunit ribosomal DNA of a new yeast species, Trichosporon domesticum and related species. Microbiol Immunol. 1997, 41:571-3. 10.1111/j.1348-0421.1997.tb01893.x

22. Makino H, Fujimoto J, Watanabe K: Development and evaluation of a real-time quantitative PCR assay for detection and enumeration of yeasts of public health interest in dairy products. Int J Food Microbiol. 2010, 140:76-83. 10.1016/j.ijfoodmicro.2010.02.004

23. Biswas SK, Wang L, Yokoyama K, Nishimura K: Molecular phylogenetics of the genus trichosporon inferred from mitochondrial cytochrome B gene sequences. J Clin Microbiol. 2005, 43:5171-8. 10.1128/JCM.43.10.5171-5178.2005

24. Odabasi Z, Mattiuzzi G, Estey E, et al.: Beta-D-glucan as a diagnostic adjunct for invasive fungal infections: validation, cutoff development, and performance in patients with acute myelogenous leukemia and myelodysplastic syndrome. Clin Infect Dis. 2004, 39:199-205. 10.1086/421944

25. Suzuki K, Nakase K, Kyo T, et al.: Fatal Trichosporon fungemia in patients with hematologic malignancies . Eur J Haematol. 2010, 84:441-7. 10.1111/j.1600-0609.2010.01410.x

26. Yamagata E, Kamberi P, Yamakami Y, Hashimoto A, Nasu M: Experimental model of progressive disseminated trichosporonosis in mice with latent trichosporonemia. J Clin Microbiol. 2000, 38:3260-6. 10.1128/JCM.38.9.3260-3266.2000

27. Fox A: Mass spectrometry for species or strain identification after culture or without culture: past, present, and future. J Clin Microbiol. 2006, 44:2677-80. 10.1128/JCM.00971-06

28. Bader O, Weig M, Taverne-Ghadwal L, Lugert R, Gross U, Kuhns M: Improved clinical laboratory identification of human pathogenic yeasts by matrix-assisted laser desorption ionization time-of-flight mass spectrometry. Clin Microbiol Infect. 2011, 17:1359-65. 10.1111/j.1469-0691.2010.03398.x

29. Mekha N, Sugita T, Ikeda R, Nishikawa A, Autthateinchai R, Poonwan N, Sawanpanyalert P: Genotyping and antifungal drug susceptibility of the pathogenic yeast Trichosporon asahii isolated from Thai patients. Mycopathologia. 2010, 169:67-70. 10.1007/s11046-009-9225-5

30. Clinical and Laboratory Standards Institute: Referances method for broth dilution antifungal susceptibility testing of yeasts. Barbara D. Alexander (ed): Clinical and Laboratory Standards Institute, Wayen, PA; 2008. http://medicine.kaums.ac.ir/UploadedFiles/angalshenase/M27S3\%20Third\%20International\%20Supplement.pdf.

31. Cuenca-Estrella M, Moore CB, Barchiesi F, et al.: Multicenter evaluation of the reproducibility of the proposed antifungal susceptibility testing method for fermentative yeasts of the Antifungal Susceptibility Testing Subcommittee of the European Committee on Antimicrobial Susceptibility Testing (AFST-EUCAST). Clin Microbiol Infect. 2003, 9:467-74. 10.1046/j.1469-0691.2003.00592.x

32. Diaz MR, Fell JW: High-throughput detection of pathogenic yeasts of the genus trichosporon. J Clin Microbiol. 2004, 42:3696-706. 10.1128/JCM.42.8.3696-3706.2004

33. Pfaller MA, Diekema DJ, Gibbs DL, et al.: Results from the ARTEMIS DISK Global Antifungal Surveillance study, 1997 to 2005: an 8.5-year analysis of susceptibilities of Candida species and other yeast species to fluconazole and voriconazole determined by CLSI standardized disk diffusion testing. J Clin Microbiol. 2007, 45:1735-45. 10.1128/JCM.00409-07

34. Girmenia C, Pagano L, Martino B, et al.: Invasive infections caused by Trichosporon species and Geotrichum capitatum in patients with hematological malignancies: a retrospective multicenter study from Italy and review of the literature. J Clin Microbiol. 2005, 43:1818-28. 10.1128/JCM.43.4.1818-1828.2005

35. Bassetti M, Bisio F, Di Biagio A, et al.: Trichosporon asahii infection treated with caspofungin combined with liposomal amphotericin B. J Antimicrob Chemother. 2004, 54:575-7. 10.1093/jac/dkh337

36. De Hoogs GS Guarro J, Gene J, Figueras MJ: Atlas of clinical fungi. de Hoog GS, Guarro J, Gené J, Figueras MJ (ed): Centraalbureau voor Schimmelcultures, Utrecht, Netherlands; 2000. 
https://www.cabdirect.org/cabdirect/abstract/20013005530.

37. Kalkanci A, Sugita T, Arikan S, et al.: Molecular identification, genotyping, and drug susceptibility of the basidiomycetous yeast pathogen Trichosporon isolated from Turkish patients. Med Mycol. 2010, 48:141-6. 10.3109/13693780902977984

38. Lemes RM, Lyon JP, Moreira LM, de Resende MA: Antifungal susceptibility profile of Trichosporon isolates: correlation between CLSI and etest methodologies. Braz J Microbiol. 2010, 41:310-5. 10.1590/S151783822010000200008

39. Sun W, Su J, Xu S, Yan D: Trichosporon asahii causing nosocomial urinary tract infections in intensive care unit patients: genotypes, virulence factors and antifungal susceptibility testing. J Med Microbiol. 2012, 61:1750-7. 10.1099/jmm.0.049817-0

40. Yang YL, Liu YW, Chen HT, Tsai MS, Chu WL, Lo HJ: Genotype analysis based on intergenic spacer 1 sequences of Trichosporon asahii collected in Taiwan. Med Mycol. 2013, 51:880-3. 10.3109/13693786.2013.800240

41. Arabatzis M, Abel P, Kanellopoulou M, et al.: Sequence-based identification, genotyping and EUCAST antifungal susceptibilities of Trichosporon clinical isolates from Greece. Clin Microbiol Infect. 2014, 20:77783. 10.1111/1469-0691.12501

42. Taverna CG, Córdoba S, Murisengo OA, Vivot W, Davel G, Bosco-Borgeat ME: Molecular identification, genotyping, and antifungal susceptibility testing of clinically relevant Trichosporon species from Argentina. Med Mycol. 2014, 52:356-66. 10.1093/mmy/myt029

43. Montoya AM, Sánchez González A, Palma-Nicolás JP, Gómez-Treviño A, González JG, González GM: Genotyping, extracellular compounds, and antifungal susceptibility testing of Trichosporon asahii isolated from Mexican patients. Med Mycol. 2015, 53:505-11. 10.1093/mmy/myv009

44. Almeida AA, Crispim Bdo A, Grisolia AB, Svidzinski TI, Ortolani LG, Oliveira KM: Genotype, antifungal susceptibility, and biofilm formation of Trichosporon asahii isolated from the urine of hospitalized patients. Rev Argent Microbiol. 2016, 48:62-6. 10.1016/j.ram.2015.11.005

45. Rastogi V, Honnavar P, Rudramurthy SM, Pamidi U, Ghosh A, Chakrabarti A: Molecular characterisation and antifungal susceptibility of clinical Trichosporon isolates in India. Mycoses. 2016, 59:528-34. 10.1111/myc. 12511

46. Singh S, Capoor MR, Varshney S, Gupta DK, Verma PK, Ramesh V: Epidemiology and antifungal susceptibility of infections caused by Trichosporon species: an emerging non-Candida and nonCryptococcus yeast worldwide. Indian J Med Microbiol. 2019, 37:536-41. 10.4103/ijmm.IJMM_19_146

47. Mehta V,Chander J,Gulati N, et al.: Epidemiological profile and antifungal susceptibility pattern of Trichosporon species in a tertiary care hospital in Chandigarh, India. Current Medical Mycology. 2021, 7:1924. $10.18502 / \mathrm{cmm} \cdot 7 \cdot 1.6179$ 